\title{
Namghar: Aesthetics and Identity of Social Cultural Institutional Architecture in Assam, India
}

\author{
Charu Monga1* and Amarendra Kumar Das² \\ ${ }^{1}$ Assistant Professor, Department of Design, Indian Institute of Technology (IIT) \\ Guwahati, India \\ ${ }^{2}$ Professor, Department of Design, Indian Institute of Technology (IIT) Guwahati, India \\ *Corresponding author: Charu Monga, Assistant Professor, Department of Design, \\ Indian Institute of Technology (IIT) Guwahati, India, Email: charumonga2016@gmail.com
}

\section{Research article \\ Volume 2 Issue 3}

Received Date: May 11, 2018

Published Date: June 01, 2018

DOI: $10.23880 /$ eoij-16000152

\section{Abstract}

This paper concerns the application of visual ethnographic research to preserve the cultural identity of structures like Namghar located at the banks of Brahmaputra in Assam. Namghar are an important socio-cultural institution, whose design elements are essential and symbolic for binding the entire community especially belonging to various areas of Assam. However, rapid urbanization and changing lifestyle has led to variations in design elements of Namghar. This study on these variations in design elements will be essential in preserving the essence, harmony among diverse communities as well as heritage of Assam. The objectives of this study are to compare variations in design elements especially colour variations of Namghar located at different locations within Assam. Field observations of outer overall structure, elements as well as interior structure were made. Colour palate was identified and the visuals were analyzed. Similarities and differences among key architectural elements will be compared and discussed. Cultural aesthetics elements were explored with visual ethnography on architectural elements among Namghars in various locations. It is identified, discussed with reference to semiotics and semantics of cultural construction. This paper seeks to arouse the issues of cultural loss of Namghar and possibility of colour as a binding design element among the architecture of Namghar.

Keywords: Namghar; Aesthetics; Colour; Architectural elements; Cultural preservation

\section{Introduction}

Namghar are social-cultural institutions that were introduced between $12^{\text {th }}$ and $15^{\text {th }}$ century AD in Assam by the Vaisnavite Saint Srimanta Shankardeva. These were introduced as a consequence of Vaishanava Bhakti movement. The movement was initiated when inequality, suppression of lower class and mal-practices in Hinduism reached its peak in $15^{\text {th }}$ Century [1]. This movement objective is to bring everyone into the same level and gave birth to equality. Namghar are basic building blocks 
of Assamese society and played an essential role in unifying people from various diversities.

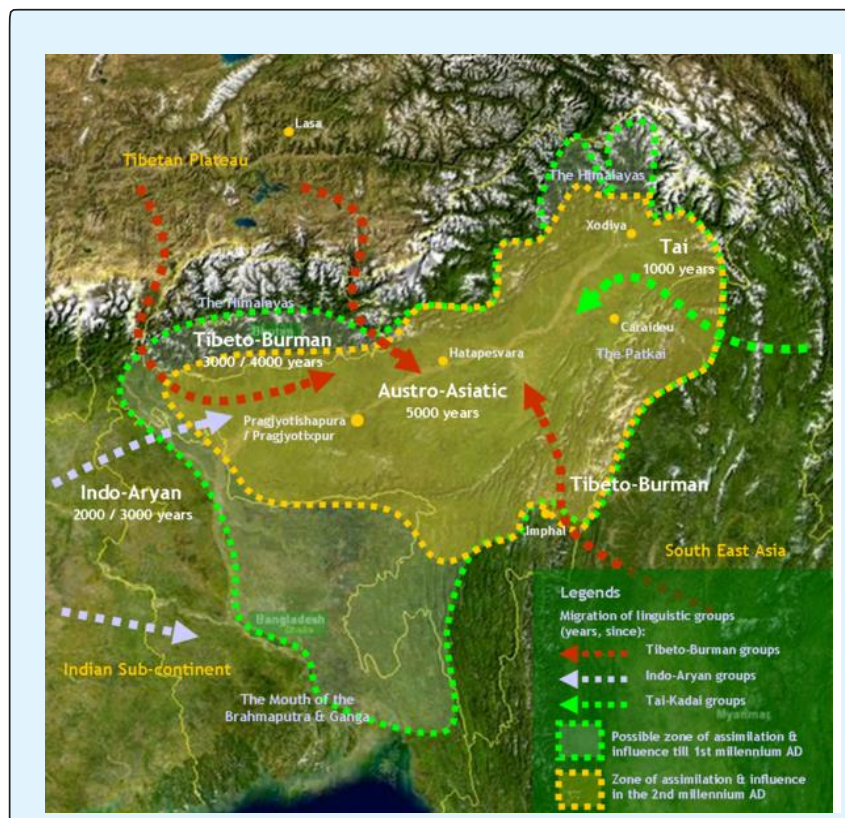

Figure 1: Map illustrating directions of movement of tribes into Assam [2].
It is not only a place of worship but also a central meeting point, where all the people discuss about the issues related to their society. Namghar also called kirtan ghar. It works as meeting points of congregations, as well as theatre of dramatic performances like Bhoana, Raas Lila and many others [1].

The Satra institutions are unique institution with multidisciplinary socio-religious, cultural, art and also architectural domain with its distinctive characteristics derived from the Bhakti movement [3]. From architectural point of view, the design of the above institution has been also influenced by various external (or foreign) tribes, which have travelled from different parts such as Bhutan, Thailand, Mongolia, and other parts of East Asia [4,5]. Figure 1 illustrates the movement of people from different neighboring parts around Assam [2]. Assamese culture is developed under the great dynasties of Pragjyotisha-Kamrupa, during the first millennium $\mathrm{AD}$. "The modern name of the province, Assam, is actually of quite recent origin. It is connected with the Shan invaders who entered the Brahmaputra Valley in the beginning of the thirteenth century A.D., and who were known as Ahoms" [6]. It is developed due to acculturation of different ethno-cultural groups under various sociopolitical systems in different periods of history [7].

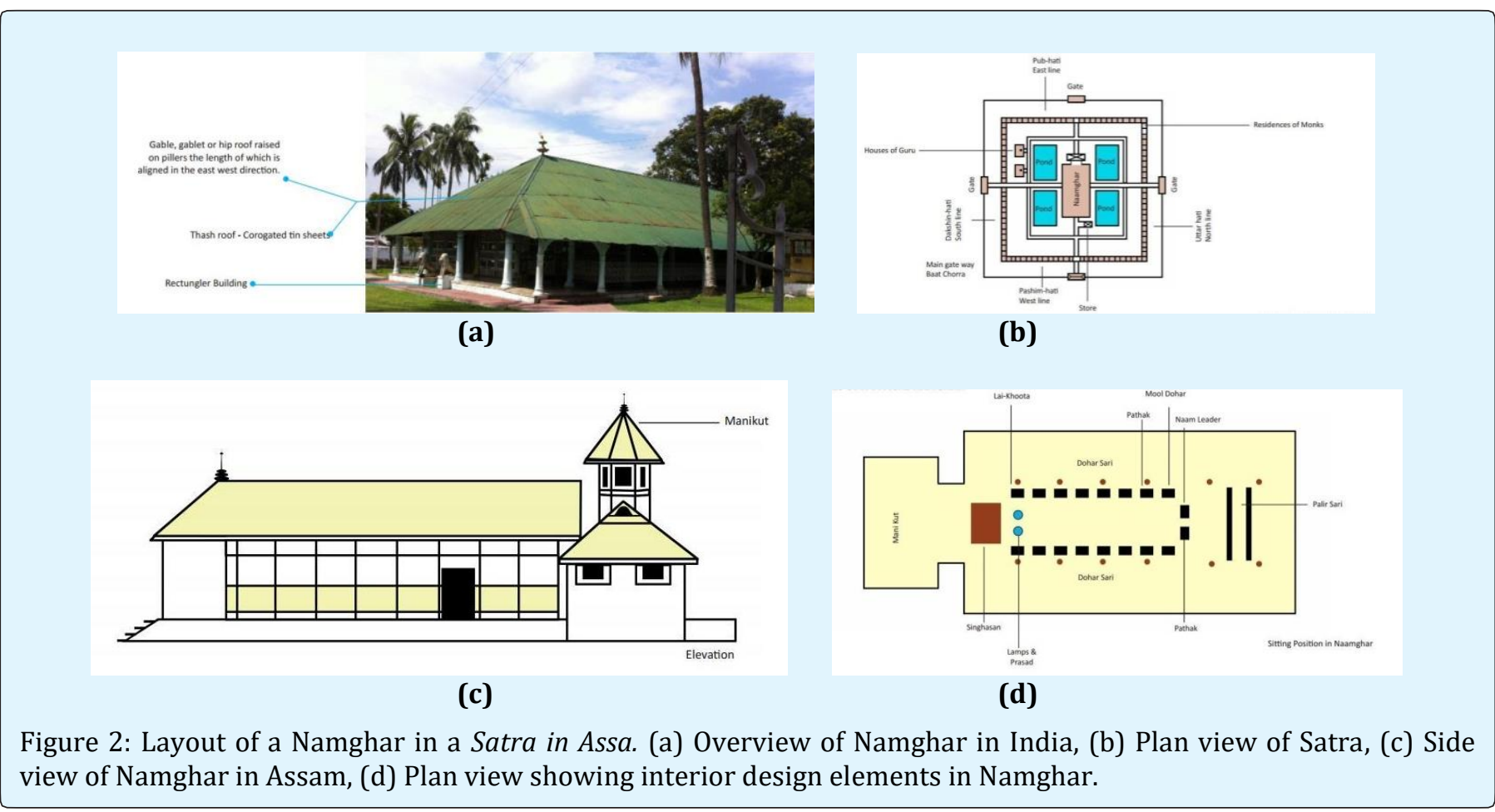

Charu Monga and Amarendra Kumar Das. Namghar: Aesthetics and Identity of Social Copyright $(\subset$ Charu Monga and Amarendra Kumar Das. Cultural Institutional Architecture in Assam, India. Ergonomics Int J 2018, 2(3): 000152. 
Architecture is the most pronounced introduction of a land and its people radiates the spirit of the place, its cultural richness and the aesthetic taste of the people. A culmination of the tangible and intangible qualities, it is the spirit of a place that gives visitors a wholesome experience of the place and connects them to its cultural landscape. Present day architecture however advocates global homogeneity, thereby dissolving the indigenous distinctiveness that imparted the identity and beauty in a place. Figure 2 shows the overview and architectural layout (plan and side layout) of Satra. It can be clearly seen that the Satra consists of a Namghar (at center) surrounded by various other places such as houses of monks, gurus, pond etc. The Namghar is one of the most important parts of Satra as various rituals, kirtan and also group discussions are carried in it. However, due to rapid urbanization in developing countries like India, cities have lost their spirit and have become soul less. In a country like India, the concept of identity conservation and revival is far from being realized in the rat race towards the achievement of the western definitions of high-end living. Therefore, it is essential to quantify the essential design details (color, shape, form etc) of elements of these social-cultural institutions for preservation and also future reconstruction. Color is one of the important design detail that is required for preservation and also future reconstruction.
The objective of this study is to quantify color palette in various elements of Namghar (Manikut, Main gate, sculptures, relief work, floral designs). The study seeks to arouse the issues of cultural loss of Namghar and possibility of colour as a binding design element among the architecture of Namghar.

\section{Research Methodology}

The methodology includes a comprehensive multiple set of field visual survey and studio analysis. In laboratory, Machine-learning algorithm [8] is adopted for generating color palette. The description of each method is reported in following sections.

\section{Field Visual Surveys}

Figure 3 presents the map showing the positions of Namghar that were selected for field investigation. As seen from the map, the Namghars seems to be widespread across Assam, with most of them covered in and around Guwahati. In total, field investigation of 24 Namghars was conducted. Namghars were selected tactfully so as to cover all three regions such as rural, semi-urban and urban region. In addition, they were also selected based on their time history of establishment. However, in this study only color palette analysis for only one namghar (i.e. Srimanta Shankradev Kala Kriti Kendra) is presented.

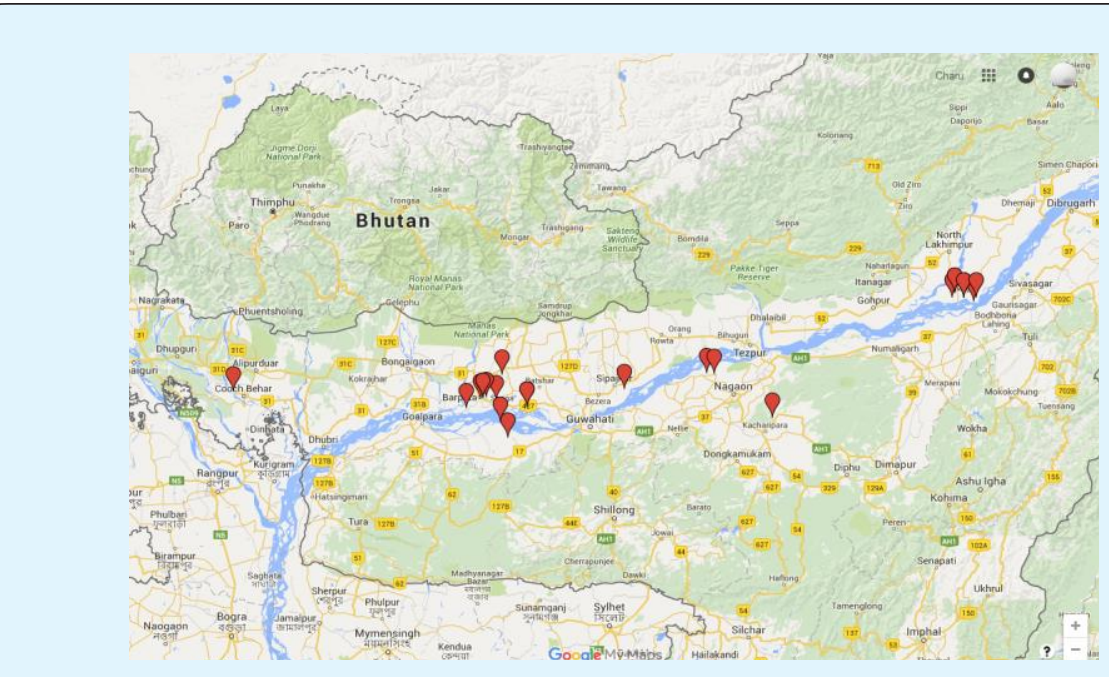

Figure 3: Map showing positions of Namghar that were investigated in this study.

In field visit, visuals of different elements (Manikut, Chandrataap, Sarai, Floral designs) were captured using high-resolution cameras. Regular (a) Go Pro camera and (b) Nikon 700Dcameras were used. Go Pro Camera allows still capturing of interviews and also activities of
Namghar. Simultaneously, during the first field visit, instant interviews were held to get basic information of Namghar and its design elements. The data collected from field visual survey include visual photographs, videos, voice recordings and also basic qualitative information 
(Name, age, location, households, adhikiri (main person associated) related to Namghar. The visual photographs were then analyzed using K-Algorithm tool to capture color pallets. The details related to procedures adopted for $\mathrm{K}$-algorithm is provided in next section.

\section{Color Palette Generator Using K-Means Clustering Algorithm}

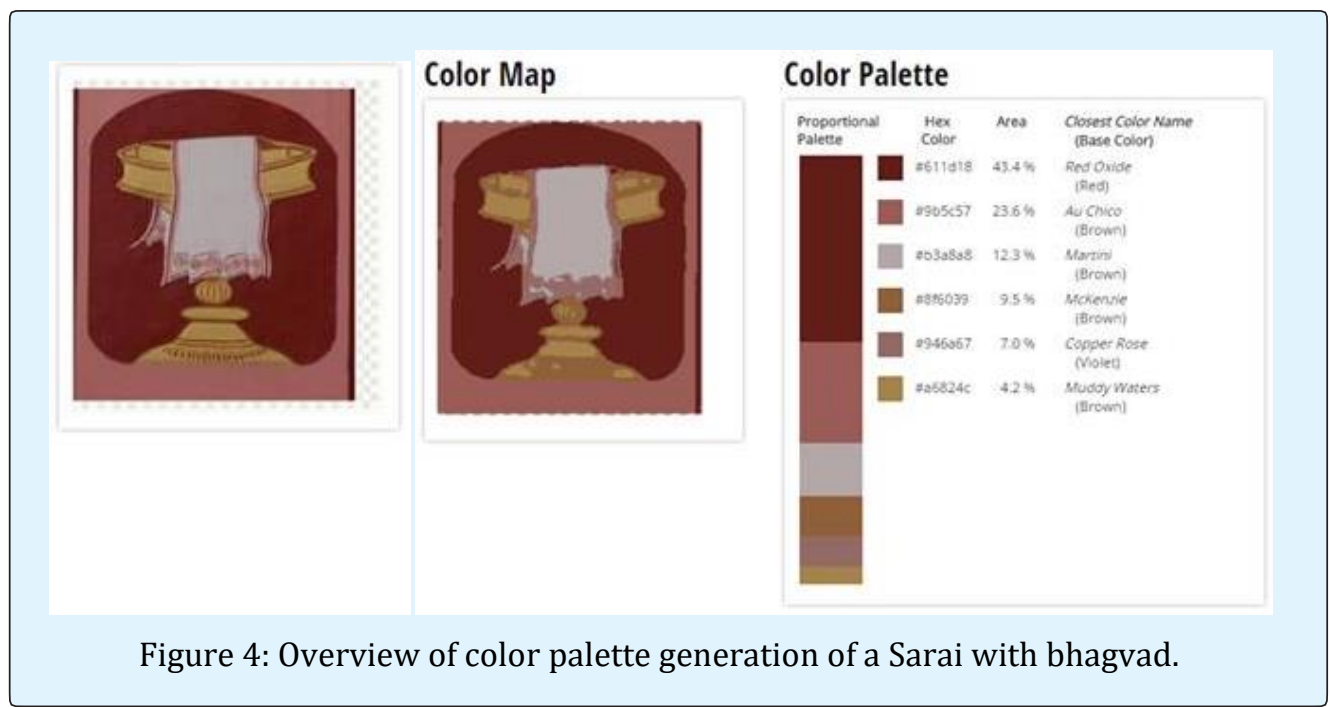

Color palette is an essential output of color quantization process. Color palette provides information on the dominant list of colors of that particular image. The color palette has been used effectively by various researchers in field of image processing and designs [912]. In this study, an open source program "Color palette generator" was adopted for color palette quantification of various design elements of Namghar. The tool allows generating color palette of the collected visual images of various interior and exterior design elements of Namghar. The adopted process is similar to the one adopted by Delon, et al. [13] and Chang et al. [14].

\section{Interpretation of Color Palette of Various Elements of Namghar}

Figure 5 shows the actual image of the main gate (left) and its colored palette (right). As seen, the colored palette consists of proportion of colors that appear on the main gate along with their proportion (\%). As observed, the crater brown is the most dominant color followed by the grey and blue color. The most dominant color appears mainly on the sculpture (Lions; at top of gate) on the main gate, the doba (by Bhakat) and also written scripts. Greyish color appears on the bhakat whereas light blue color is found to be dominated on the background of bhakat painting on wall [15].

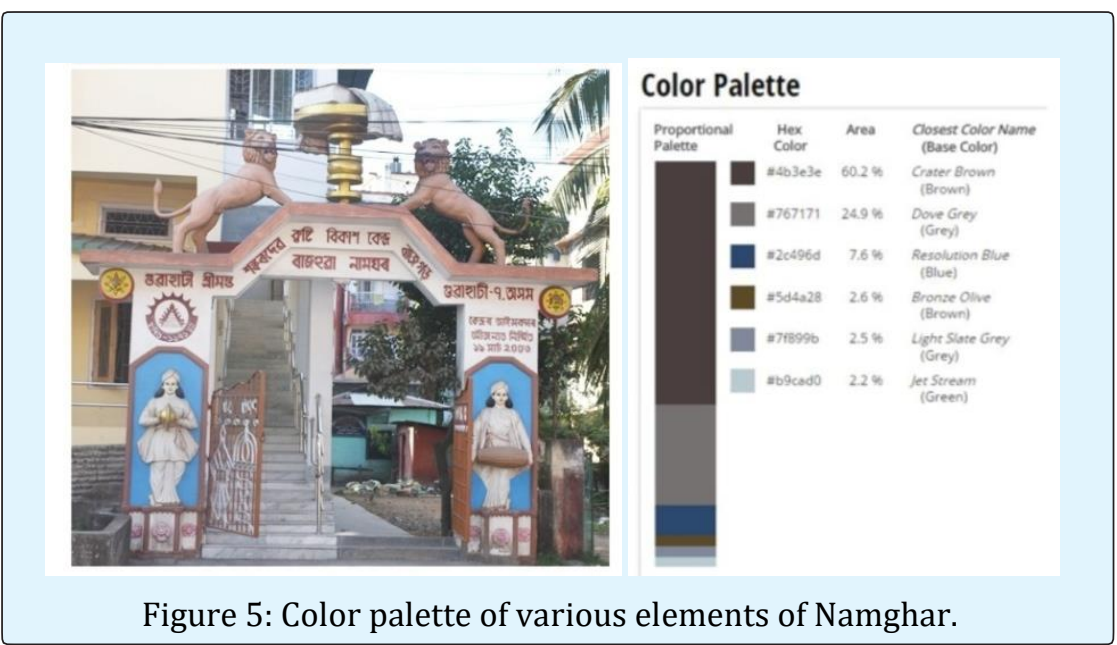

Charu Monga and Amarendra Kumar Das. Namghar: Aesthetics and Identity of Social Copyright@ Charu Monga and Amarendra Kumar Das. Cultural Institutional Architecture in Assam, India. Ergonomics Int J 2018, 2(3): 000152. 


\section{Floral Design on Door}

Color palette for floral design (Figure 6) on door shows the domination of bright red color (66.2\%) followed by pink $(17.7 \%)$ and other such as blue, green etc. As observed from the actual image, the bright red is present mainly on the boundaries and background while the flower (lotus) itself is decorated with pink color and green. The following analysis indicate that it is important to analyze the proportions of color with respect to actual object/painted on wall. The pink color resembles that of actual lotus, which is one of the essential elements of 10 forms of Vishnu (Dashavatar). Lotus leaves are dominated with variant of pink color while its petals with green color and light blue. These floral designs are mainly adorned at various structural elements such as doors, windows, jail works, manikut and walls. It should be noted that main gate (previous figure) do not highlight presence of bright red or pink color or green.

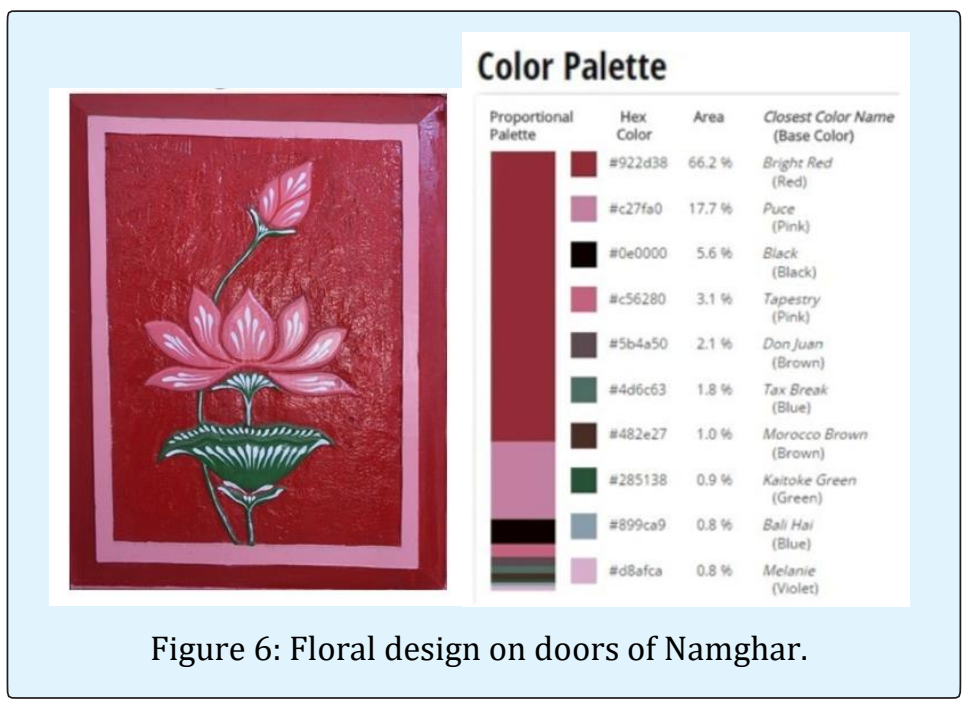

Figure 7 shows actual image and also color palette of floral design (lily flower) also adorned at various structural elements of Namghar. The dominated color is red followed by green, yellow, blue respectively. The red color is found to be along outer side while floral itself is dominated with yellow and green color with small patches of light blue and red. The leaves are dominated by yellow color and tendrils with green color. Yellow was almost absent in previous figure, while the color of tendrils (branches) were similar to this figure.

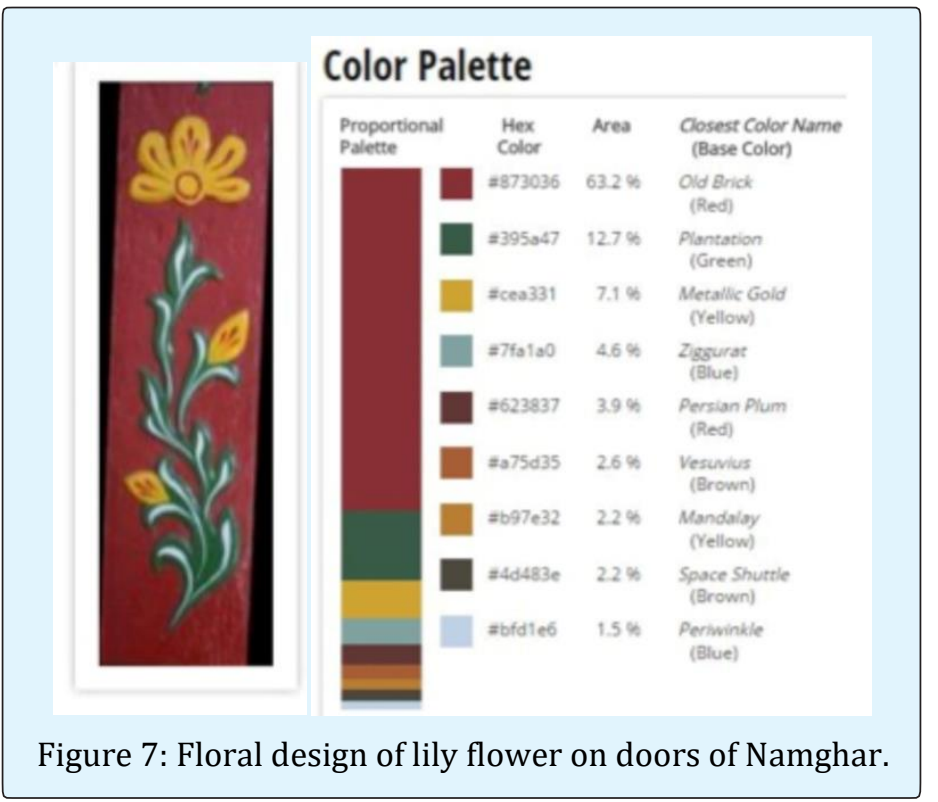

Charu Monga and Amarendra Kumar Das. Namghar: Aesthetics and Identity of Social Copyright $(C$ Charu Monga and Amarendra Kumar Das. Cultural Institutional Architecture in Assam, India. Ergonomics Int J 2018, 2(3): 000152. 
Figure 8 shows the actual image and corresponding color palette of manikut. As clear from the image, the dusty grey is the most dominant color followed by horizon (blue), stack (grey), sandrift (brown) and fuscous grey (grey). Other colors such as Del rio (brown), tobacco brown (brown), shadow (green) are found to exist. The dusty grey appears not on the actual manikut but on the gohain placed on it. The actual manikut mostly dominated with horizon, stack and sandrift colors. The floral designs are represented with sandrift color while the background is with horizon color. The sculptures (lions) on each stairs of manikutare colored with sandrift too. The tomb of manikut is colored with greyish color (stack). The color analysis of manikut shows that the combination of horizon, stack and sandrift are most important for its future reconstruction. These are well-distinguished form color palette obtained for floral design and main gates in previous figures.
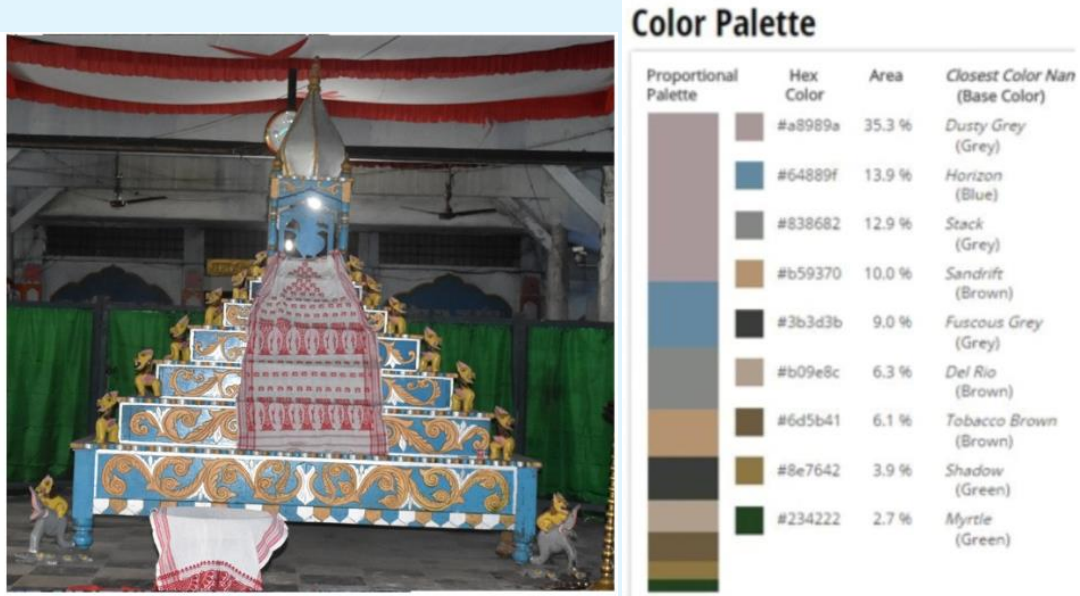

Figure 8: Color palette of manikut.

Figure 9 shows the actual image and corresponding color palette of sculpture (lion) on the main gate. As shown in color palette, Carnaby Tan is the most dominated color followed by brown, brown pod, muddy waters and peat. Carnaby Tan occupies $41 \%$ of total color with brown with $24.1 \%$ while, Brown pod, muddy waters and peat varies from 7-11\%.As clear from the image, the dusty grey is the most dominant color followed by horizon (blue), stack (grey), sandrift (brown) and fuscous grey (grey). As seen from the actual image, the top portion of lion till its neck is dominated with Carnaby Tan with brown color appearing on the main face. The lower portion below neck is dominated with brown and muddy water colors. The implication of such color palette is important while re-construction of sculptures for social cultural institution (Namghar).

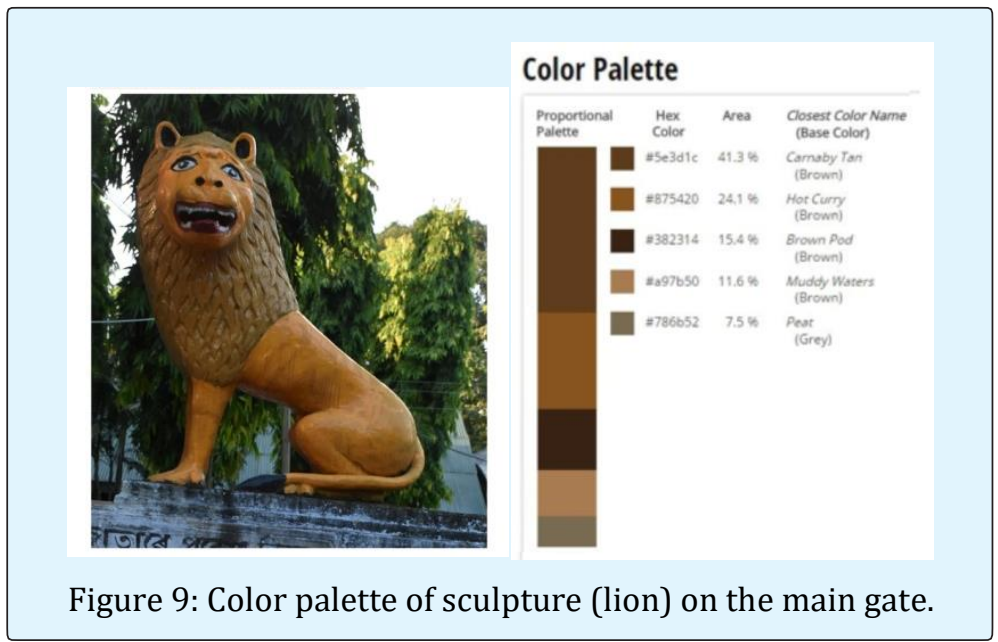

Charu Monga and Amarendra Kumar Das. Namghar: Aesthetics and Identity of Social Copyright $(C$ Charu Monga and Amarendra Kumar Das. Cultural Institutional Architecture in Assam, India. Ergonomics Int J 2018, 2(3): 000152. 
Figure 10 Actual image and color palette of one of relief on walls of Lord Krishna is shown here. As appear from the image, the color palette is mainly dominated by smalt blue $(51 \%)$ followed by Shallow green (18\%), Pavlova (10\%) and other colors (different forms of grey, green and brown). If we look closely at the image, the background of relief and body of Lord Krishna is colored with smalt blue while that of evil with shallow green. This seems to be because of maintaining certain contrast between good and the evil. Wearing on Lord Krishna is mainly decorated with Pavlova color. Other cloths are mainly colored with merlot, ferra and dove grey. While for the evil, the wearing are colored with bistre and also some olive tone and dark khaki. The black color symbolizes darkness associated with evil. The blood on the evil is shown with merlot color.

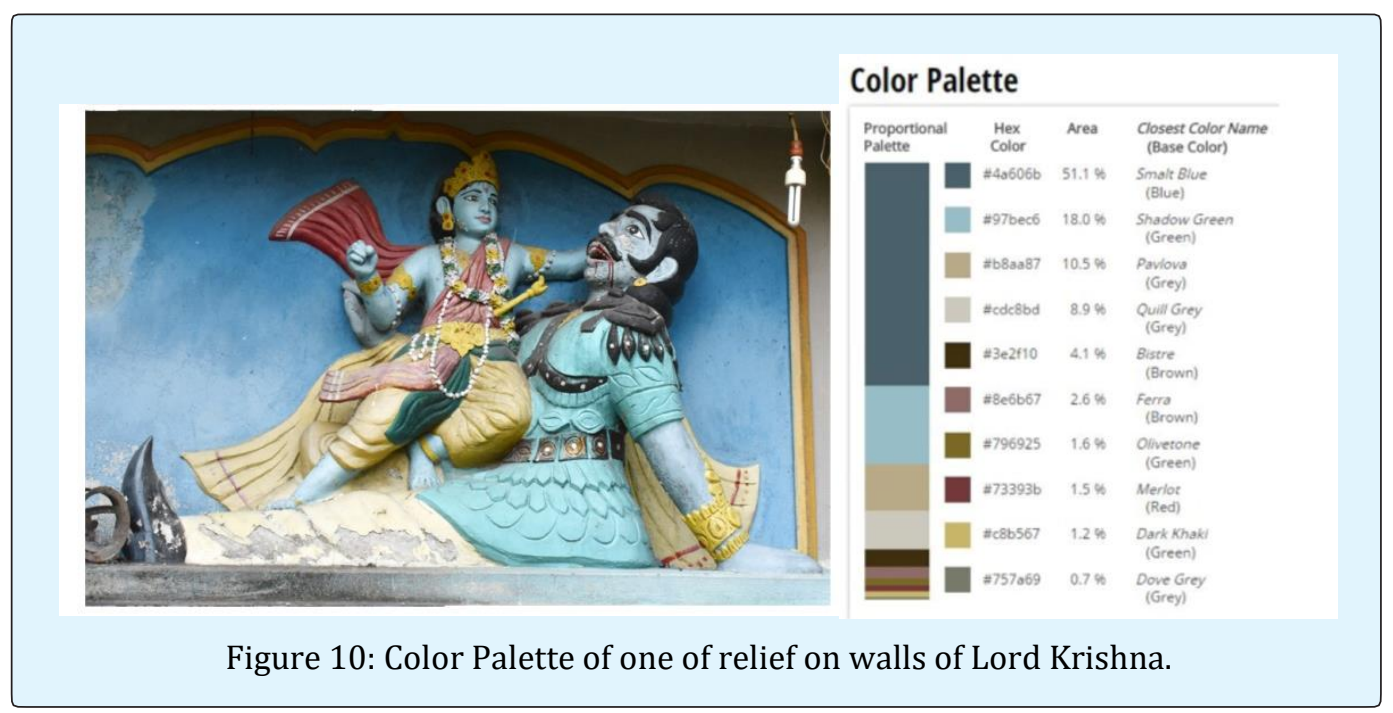

Figure 11 As compared to previous relief, the relief of boar (one from the dasavatar of Lord Vishnu) is dominated with steel blue followed by Grey chateau, Chicago, teak and mojo mainly. Other colors (Cement, dark golden, copper rust) forms very small proportion. It was found that the main body mainly decorated with steel blue with small patches of Grey chateau on the hands mainly. The dressing and other wearing on the body is mainly adorned with teak color and small portion of dark golden. The flower relief on the neck is decorated with combination of mojo, amazon and teak. The earth (on the teeth of boar) is decorated with mix of teak, steel blue and mojo to represent earth continents. The steel blue is especially used to represent water here. The shankha on the left hand is mojo colored.

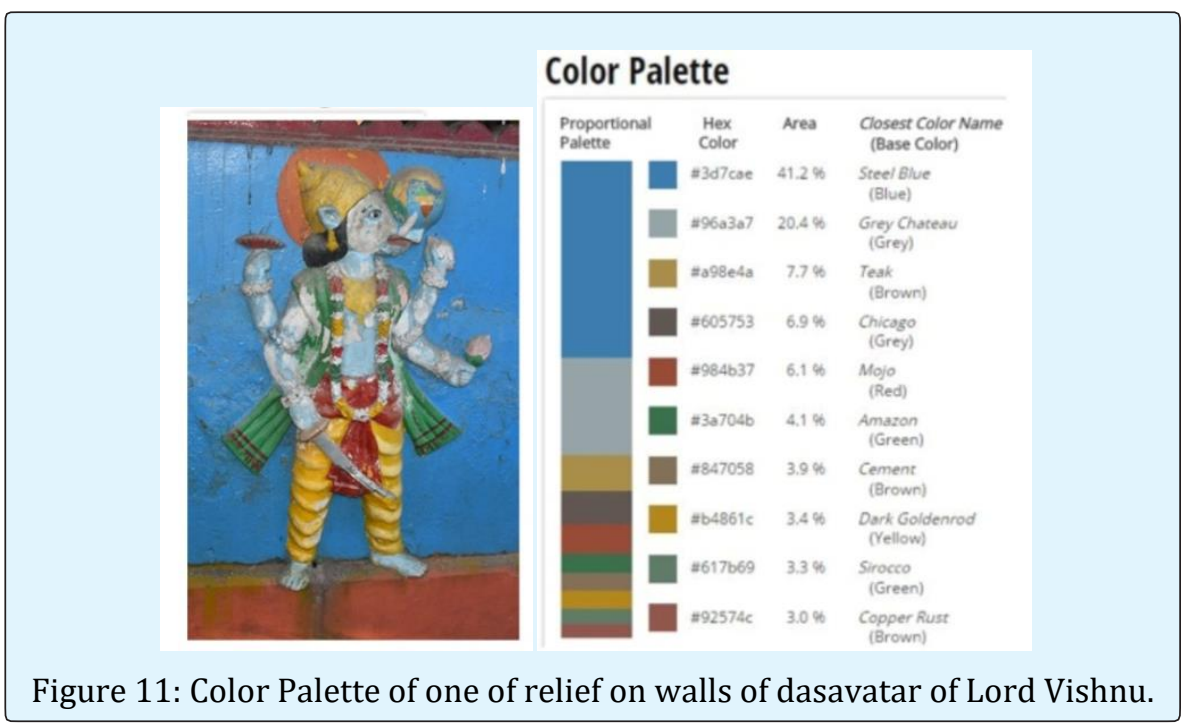

Charu Monga and Amarendra Kumar Das. Namghar: Aesthetics and Identity of Social Copyright $@$ Charu Monga and Amarendra Kumar Das. Cultural Institutional Architecture in Assam, India. Ergonomics Int J 2018, 2(3): 000152. 


\section{Ergonomics International Journal}

\section{Conclusion}

The present study analyses the color palette in various elements of Namghar. It was found that the colors palette varies significantly across different elements. Even within a same element, the color may vary hugely. It was found that the main gate is mainly dominated with the crater brown and dove grey. For sculptures such as lion on outer gate, the top portion till half is dominated with Carnaby Tan while its face is dominated with shade of brown and muddy water (brown) colors. Floral designs are painted usually on bright red background while lotus leaves with puce and lily leaves with metallic gold. The petioles of both the flowers are decorated with plantation green color. The Manikut itself is decorated with dusty grey and horizon blue colors. The relief of god and also of dasavatar on walls of Namghar is mainly represented with different forms of blue color. The cloths are mainly colored using different forms of yellow, red or green for god, however, it is black for evil. The blue color usually represents sea (or water) and the relief on walls represents a certain section of hindu mythology from Mahabharta.

\section{References}

1. Neog M (1998) Sankaradeva and the Vaishnava Renaissance in Assam. 2 ${ }^{\text {nd }}$ (Edn.), Sankaradeva: studies in culture. Srimanta Sankaradeva-Sangha, Guwahati, pp: 46-55.

2. Bhagawati AC (2002) Ethnic Identities in North-East India. N K Bose Memorial Lectures, Vihangama: IGNCA Newsletter.

3. Barkakoti K (2001) Art and Architecture in the Sattra Institutions of Assam Glimpses of the Vaisnava Heritage of Assam 43: 168-175.

4. Guha Amalendu (1984) Pre-Ahom Roots and the Medieval State in Assam: A Reply. Social Scientist 12(6): 70-77.

5. Taher Mohammad (1993) The Peopling of Assam and contemporary social structure. In: Ahmad Aijazuddin
(Ed.), Social Structure and Regional Development. Rawat publications, New Delhi.

6. Barua B kr (2011) A Cultural History of Assam. $5^{\text {th }}$ (Edn.), Bina Library, Guwahati.

7. Gait E (2013) A History of Assam. 2nd (Edn.), Bina Library, Guwahati.

8. Linde Y, Buzo A, Gray R (1980) An algorithm for vector quantizer design. IEEE Trans on Communication pp: 84-95.

9. Meier BJ, Spalter AM, Karelitz DB (2004) Interactive color palette tools. IEEE Computer Graphics and Applications 24(3): 64-72.

10. Tsai P, Hu YC, Chang CC (2004) A color image watermarking scheme based on color quantization. Signal Processing 84(1): 95-106.

11. Ke Y, Tang X, Jing F (2006) The design of high-level features for photo quality assessment. Computer Society Conference on Computer Vision and Pattern Recognition (CVPR'06), IEEE 1: 419-426.

12. Heer J, Stone M (2012) Color naming models for color selection, image editing and palette design. In Proceedings of the SIGCHI Conference on Human Factors in Computing Systems pp: 1007-1016.

13. DelonJ, Desolneux A, Lisani JL, Petro AB (2005) Automatic color palette. IEEE International Conference on Image Processing.

14. Chang H, Fried O, Liu Y, Di Verdi S, Finkelstein A (2015) Palette-based photo recoloring. ACM Transactions on Graphics (TOG) 34(4): 139.

15. Haokip TL (2015) Ethnic Separatism The Kuki-Chin Insurgency of Indo- Myanmar/Burma. South Asia Research 35(1): 21-41. 